\title{
DA INEXECUCÃO DAS OBRIGAÇÕES E OS JUROS ABUSIVOS
}

Rozane da Rosa Cachapuz

SUMARIO. 1. Introduço - Da Inexecuçäo das Obrigaçóes - 2. Noçoes Introdutorias 2.1. Evolução Hisiórica - 3. Do Inadimplemento - 3.1. Definição - 3.2. Definição - 4. Do Inadimplemento (Absoluto e Relativo) - 5. Da Mora, Conceito - 6. Juros Abusivos - 7. Conchusão - 8. Bibliografia

RESUMO: A inexecução das obrigaçoes ocorre de forma acentuada em nosso Pais, e os juros cobrados são totalmente abusivos, pois, que sem paramethos legais. É hora de mudar tais atitudes, através da definiçäo da timitacáo constitucional!

PALAVRAS-CHAVE: obrigacoes, inadimplemento, mora "debitoris" $e$ mou "accipiendi", juros abusivos.

ABSTRACT: The misdoing of an obligation happens in a accentuated way in our country and the charged interest are totally abusive, for the absence of legal parameters. It's time to change these attitudes, through the constitulional limilation!

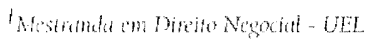




\section{INTRODUCCÃO}

$E_{m}$ regra, as obrigaçōes são constituidas para serem cumpridas, entretanto, na maioria dos casos, o próprio sistema em que vivemos impede a sua concretização. Prova disto é que a própria legislação prevê os casos que o cumprimento não é possivel (caso fortuito ou força maior).

No entanto, o credor tem amparo legal para reaver o seu crédito, quando não consegue de forma amigável, socorrendo-se do Judiciário para a regularização da obrigação.

O principal ponto considerado é a falta de regularização na taxação de juros, levando as instituições financeiras a parâmetros totalmente absurdos e ou abusivos, encontrando apoio em parte, no Judiciário que entende que a limitaçäo constitucional, não é auto - aplicável.

Destarte, năo há como deixar de considerar que existe uma preocupação bastante grande de juristas em modificar a determinação do STF; posicionando-se de forma contrária e já movimentando-se para uma nova avaliação do assunto.

\section{DA INEXECUÇÃO DAS OBRIGAÇÕES}

\section{NOÇÕES INTRODUTÓRIAS}

Do latim obligatione ${ }^{2}$; dever; encargo, compromisso. Tecnicamente, obrigação é espécie do gênero dever, reservando-se o termo para clesignar o dever correlato a um direito de crédito33.

Quando empregada na acepção puramente lécnica, ainda assim se usa em vários significados. Ora designa um dos lados da relação obrigacional, scja o crédito, seja a dívida; ora o fato que lhe dá nascimento, vale dizer, a sua lonte; ora o instrumento de sua prova ${ }^{4}$.

Em regra, as obrigaçoes devem ser cumpridas, ou seja, fielmente executadas. O devedor encontra-se adstrito a realizar uma prestação que

\footnotetext{
2 Fercin, Aurdio Buarque de Holanda. "Novo Dicionario, Auélio da Língla Portuguesa, Editona Nowa Fronteba, $2^{*}$ edicuro, Rio de Janeiro, P. 1209

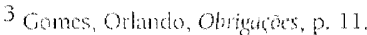

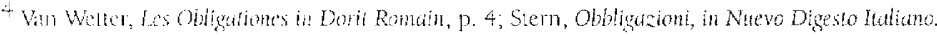


integra o conteúdo da relação obrigacional.

O Direito das Obrigaçóes exerce grande influência na vida econômica, uma vez que regula relações de infra - estrutura social, dentre as quais se salientam por sua relevância política, as de produção e as de troca. É através de relaçoes obrigacionais que se estrutura o regime econômico, sob formas definidas de atividade produtiva e permuta de bens, retratando, pois, a estrutura econômica da sociedade.

A rede que distende apanha toda pessoa humana, como nota Hedemann ${ }^{5}$. Nas sua justa observação, relações obrigacionais que se travam cada dia ascendem a milhöes. Toda a nossa vida se desenvolve, com efeito numa atmosfera em que o Direito das Obrigações está presente. Assim, o conbecimento de sua dogmática e de sua técnica interessa, fundamentalmente ao jurista.

O efeito natural da obrigação, pois o objetivo para o qual tende esta é o implemento da prestação.

O adimplemento da obrigaçăo é a regra, e o inadimplemento a exceção, por tratar-se de uma anomalia no direito obrigacional, que representa um rompimento da paz social, capaz de provocar a reação do credor, que poderá lançar mão de certos meios para satisfazer o seu crédito.

A consequência do inadimplemento da obrigação, é, assim, o dever de reparar o prejuizo. De modo que, se a prestação não for cumprida, nem puder sê-lo, proveilosamente para o credor, apura-se qual o dano que o mesmo experimentou, impondo-se ao inadimplente o mister de indenizá-lo.

\subsection{Evolução Histórica}

O direito romano na época, na hipótese de não cumprimento de uma obrigaçăo, autorizava o credor, mediante a observância de certas formalidades, a apoderar-se da pessoa vinculada, em regra o devedor com o que se pretendia, sobretudo conseguir que este, ou alguém por si efetuasse a prestação.

A manus iniecto consistia precisamente no antiquíssimo ritual que se utilizava no apoderamento pelo credor do responsável, a fim de dispor dele,

\footnotetext{
5 Iledemenn. Derecho de Obrigectones, p. 30 "apud" Gomes, Orlando. Obrigaçes, p.3.
} 
reduzindo-se à escravidão, (venda "trans Tiberim") ou surrando-o até a morte. Tal resultado só poderia evitar-se com a intervenção de um defensor (vindex), que, opondo-se à reclamação executiva, corria, ahiás o risco de ser condenado ao dobro da dívida, caso se demonstrasse a exigibilidade da mesma.

A Lei das XII Tábuas, pelos meados do século V a.C., mitigou este procedimento, porquanto o submeteu a determinados requisitos. Novo passo de humanização coube a "Lex Poetelia Papiria de Nexis", em 326 a.C. que aboliu a possibilidade de o executado ser morto ou vendido como escravo, licando o credor apenas com o direito de mantê-lo numa situação de çuase - escravo (addictus), para que, através do trabalho, resgatasse a sua servidão por dívidas.

Na época clássica, a execução apresenta, de ordinário natureza patrimonial. Consequentemente, a "actio iudicati" conduzia, antes de mais nada, à venda dos bens do devedor e só na falta destes, a título subsidiário, portanto, implicava uma execuçäo pessoal conducente à mencionada quase - servidão em que o "addictus" fornecia trabalho ao credor".

Ao longo da história do Direito Português, como nos outros ordenamentos jurídicos, encontra-se a prisão por dívidas. Desde cedo, porém, a legislação geral se ocupa da matéria e procura imprimir-lhe moderação, em contraste com o disposto pelas fontes visigóticas, que sobrevivem na manifesta rudeza de certos preceitos de direito consuetudinários.

O mais antigo diploma, de 1258, que, entre várias providências, estabeleceu a proibição geral de captura do devedor, sendo ele solvente; a satislação do credor fazia-se pelos bens do obrigado, de acordo com o costume e foro da terra onde o mesmo estivesse.

Em 1282, determinou-se que a execução corresse, primeiro, contra os móveis e, só na sua falta ou insuficiência contra os imóveis, contando que o devedor, se casado, não agisse com fraude ou dolo em prejuizo da mulher, isto é, alienando os imóveis para que ficassem sujeitos à venda dos bens de raiz. Se o devedor procedesse com dolo ou fraude, subtraindo bens à

\footnotetext{
${ }^{6}$ A cvoluço, nas suas tinhas geris, é conbecida e exposia pelos romanistas. É imporante consultar L. Cabm! de Monciadi, Elomentos de Historia do Direito Ronano, Coimbra, 1923, vol. I. pp. 328 e seguintes, e Sebastiáo Cruz, Da "solutio", I. Fipocas Araica c Classica, Coimbra, 1962, pp. 17 e seguitules
} 
execucão, seria preso, ainda que tivesse por onde pagar a dívida, e assim permaneceria até completa satisfação do credor, salvo consentindo este em que o soltassem7.

Somente num preceito de carta de Lei de 20 de junho de 1774 parágralo 19 , pouco depois interpretado em assento da Casa da Suplicação, se aboliu a prisão por dívida, doravante apenas admitida nalguns poucos casos, como simples meio de compelir o devedor ao cumprimento, mesmo nesses estreitos limites e com nova face, o instituto ia encerrando a sua carreira. É que a tutela de direitos fundamentais reclamava, entretanto, que se suprimissem liguras de prisão destinadas não propriamente a punir, mas a coagir ao cumprimento de obrigaçōes.

Observa-se, pois, que a orientação clássica, de fundo romanístico, desenvolveu a perspectiva da obrigação que se esgota no dever de prestar e no correlato direito de exigir ou pretender a prestação.

Todavia, a cloutrina moderna, sobretudo por mérito de autores alemaes, evidenciou a estreiteza de tal ponto de vista e a necessidade de stiperá-lo. Deste modo, numa compreensão globalizante da situação jurídica crediticia, aponta-se ao lado dos deveres de prestação que, em caso de inadimplemento, não incide sobre a pessoa do obrigado mas exclusivamente sobre os seus bens.

\section{DO NNADIMPLEMENTO}

\subsection{Definição}

Para Maria Helena Diniz', o inadimplemento da obrigaçăo consiste na lalta da prestação devida ou no descumprimento, voluntário ou involuntário, do dever jurídico por parte do devedor, devendo-se ainda, acrescentar, que o inadimplemento pode se dar pelo não recebimento da obrigaç̃o, diante da injusta recusa do credor, insejando, dessa feita, ação de consignaça de pagamento, com o intuito de liberar o devedor.

Nessa mesma direção é ontendimento de Orlando Gomes ${ }^{9}$ quando alima que "verifica-se o inadimplemento no sentido estreito do vocabulo, quando - devedor näo cumpre a obrigacăo, voluntária, ou involuntariamente".

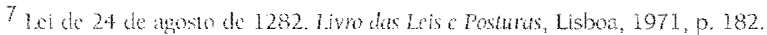

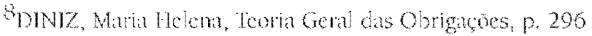

9 Comes, ortande, omingens, p. 153.
} 
Acrescenta, ainda, que pode o inadimplemento resultar de fato imputável ao devedor ou evento estranho à sua vontade, que determina a impossibilidade de cumprir. Sendo que, naquele, há inexecução culposa. Tomada a palavra culpa no sentido de violação de um dever jurídico, não pode haver dúvida quanto ao caráter culposo de todo inadimplemento voluntário. Sempre que - devedor deixa de cumprir a obrigação sem a dirimente do caso fortuito ou de forca maior configura-se procedimento culposo. Como, entretanto, o devedor inadimplente responde por perdas e danos, a doutrina tradicional funda sua responsabilidade no comportamento que tenha, referindo-se ao tipo abstrato do bom pai de familia, eis que deve conduzir-se com diligência normal.

Contra essa orientação levantam-se modernos civilistas, para os quais o devedor está adstrito a ressarcir o dano pelo exclusivo fato objetivo do inadimplemento ou da mora.

O Código Civil Alemão parágrafo 241 assinala, de modo expresso que o credor tem o direito de exigir do devedor a prestação devida. O Código Civil ltaliano de 1865, artigo 1218 afirma que o devedor está obrigado a cumprir a obrigação que contraiu.

O nosso código civil, ao consignar o princípio, segundo o qual o não cumprimento da obrigação dá ao credor o direito de exigir perdas e danos (art. 1056) não exclui, nem poderia excluir o direito que the assiste de exigir, antes de tuclo que a obrigação se cumpra tal como se convencionou, polendo-se valer, inclusive, da notificação, nos casos de mora ex persona (art. 960 CO).

Pacifici Mazzoni10 acentua muito bem que as obrigaçoes produzem cfeitos dirctos e indiretos. É efeito direto o cumprimento: efeito necessário e principal. Săo efeitos indiretos, os direitos que a lei concede ao credor, de modo a aparchá-lo para obter a execução precisa e exata da obrigaça e na sua lalta, o ressarcimento dos danos.

\section{DO INADIMPLEMENTO ABSOLUTO E RELATIVO}

Onosso Código Civil, ant. 1056, ao prescrever que, "não cumprindo

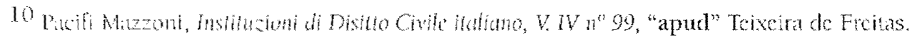


a obrigação, ou deixando de cumpri-la peto modo e no tempo devidos, reponde ao devedor por perdas e danos", está admitindo dois modos de inadimplemento: a) O absoluto: se a obrigação não foi cumprida nem poderá sê-la, e o credor não mais terá possibilidade de receber aquilo a que o devedor se obrigou, como, por exemplo, no caso de ter havido perecimento do objeto devido por culpa deste.

b) O relativo: se a obrigação não foi cumprida no tempo, lugar e forma devidos, porém poderá sê-la, com proveito para o credor, hipótese em que se terá a mora. ${ }^{11}$

Neste mesmo diapasão é o ensinamento de Agostinho Alvim², quando afirma que o inadimplemento por parte do devedor, pode ser absoluto ou, traduzir-se em simples mora: inadimplemento absoluto e inadimplemento - mora.

Já Washington de Barros Monteirol3 manifesta-se a respeito do artigo 1056 do Código Civil, entendendo que há duas situações diferentes previstas nesse dispositivo legal: a) o devedor não cumpre a obrigação; b) o devedor deixa de cumpri-los no tempo devido. Em ambas a sanção é a mesma, o devedor responde por perdas e danos, cujo pagamento se destina a recompor a situação patrimonial do credor.

\section{DA MORA}

\subsection{Conceito}

O Código Civil, no artigo 955, explicita a noção de mora, ao dispor: "Considera-se em mora o devedor que não efetuar o pagamento, e o credor que o não quiser receber no tempo, lugar e forma convencionados". Portanto, a mora vem a ser, segundo R. Limongi França ${ }^{14}$, não só a inexecução culposa da obrigação mas também a injusta recusa de recebê-la no tempo, no lugar e na forma devidos.

Silvio Rodrigues"15 afirma que "ter-se-á mora quando a obrigação não

\footnotetext{
11 Diniz, Muria Heleni, Ferid Geral Das Obrigaros, p. 297.

12 Alvim, Agostinho, Di Incxecteguo dis Obrigaçoss, p. 12.

13 Monteiro, Washinglon de Burros, Direiro das Obrigacoes, p. 364.

14 Franca, R. Limongi, Mora in "Enciclopedia saraiva do Direito", v. 53 p. 240.

15 Rodrigites, Silvio, "Direito Civil", vol. 2, pp.318-319.
} 
for cumprida no tempo, no lugar e no modo devidos, podendo sê-lo proveitosamente para o credor.

Mora é o năo pagamento culposo, bem como a recusa de receber no tempo, lugar e forma devidos ${ }^{16}$.

Constata-se por esses conceitos que tanto devedor como credor poderão incorrer em mora, desde que não tenha ocorrido fato inimputável, isto é, caso fortuito ou força maior, impediente do adimplemento da relação obrigacional.

Portanto, configurar-se-á a mora do devedor, ou mora solvendi ou debitoris quando esta não cumprir, por culpa sua, a prestação devida na forma, lempo e lugar estipulados (RT, 478: 149). Dois são, portanto, seus elementos: o objetivo, não realização do pagamento no tempo, local e modo convencionados e o subjetivo, inexecução culposa por parte do devedor.

Já a mora do credor ou mora accipiendi é, segundo R. Limongi França ${ }^{17}$, a injusta recusa de aceitar o adimplemento da obrigação no tempo, lugar e forma devidos (RT, 150: 243, 484:214, 495:218)

Constatando-se, pois, que em regra, o devedor deverá pagar no momento certo, no lugar e na forma convencionados, e ao credor cabe receber oportunamente a prestação devida no local e na forma estipulados, pois o descumprimento da obrigação induz a mora de uns ou de outro. Aquele que tiver de suportar as suas consequeencias deverá provar a ocorrência do evento hábil e criar a escusativa18.

Explica Windscheid: "Se o devedor deixou transcorrer o tempo no qual era obrigado efetuar a prestação, sem efetuá-la, está em mora. Todavia, no sentido técnico- jurídico da palavra se diz em mora somente o devedor cuja mora pode ser atribuída à culpa"19.

\footnotetext{
16 Alvim, Agostinho, "Do Inexeacüo das obrigacos", p. 16.

17 Franca, R. Limongi, Mora, p. 241.

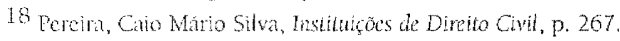

19 windscheid, "Dintio delhe Pondete", v. Il parágralo 281, in Agostinho Alvim, Op. Cilada p. 17.
} 


\section{JUROS ABUSIVOS}

F eita essa rápida análise, referente a inexecução das obrigaçoes e suas conseqüiencias, resta-nos abordar a evoluçăo de juros no direito brasileiro, no que diz respeito ao limite de sua cobrança nos empréstimos em dinheiro, no campo de ação do sistema financeiro nacional, com vistas a apreciação de seu ajuste à noma do artigo 192, parágrafo $3^{\circ}$ da Constituiçăo Federal de 1988, e ainda, a atitude de parte do judiciário, que opta pela aplicabilidade de juros, seguindo o critério adotado pelas insticuicōes financeiras.

A taxa anual de juros foi inicialmente limitada pelo Código Civil de 1916, em seu artigo 1062, em seis por cento ao ano, isto na hipótese de inexistir convenção dispondo de modo adverso, ao abrigo da autonomia de vontade das partes quanto à fixacão, por cláusula expressa de outra e diferenciada taxa de juros, na forma autorizada no artigo 1262 (CC).

O Decreto 22.626 , de 7 de abril de 1933 veio para racificar a não permissão da exorbitancia dos juros estipulaveis nos contratos privados, proibindo a contratação de remuneração de capital em patamar superior ao dobro da taxa legal, ou seja, além do limite de $12 \%$ ao ano.

No entanto, com a edição da Lei 4.595, de 31 de dezembro de 1964, que organizou o chamado Sistema Financeiro Nacional e conferiu competência normativa ao Conselho Monetário Nacional, os juros passaram a ser fixados além do limite de $12 \%$ ao ano, isto com exclusividade para os estabelecimentos bancários e instituições de crédito.

Com o advento da Constituição Federal de 1988, tentou-se a normativização dos juros, com a instituição do Artigo 192 , parágralo $3 \circ$. Entretanto, em seguida de sua promulgaçäo, o então Presidente da República José Samey aprovou parecer do Consultor - Geral da República, Saulo Ramos, concluindo no sentido de não ser auto - aplicável o preceito inscrito no relerido antigo, por entender que tal dispositivo estaria a depender da edição de noma regulamentadora.

Houve, vários pronunciamentos contrários, dentre eles o do Ministro Paulo Brossard20 quando afirmou que "a usura encontrou seu paraiso no Brasil,

20 Recurso Extrordináno n." 164.521 - RS 
e foi exalamente isso que os constituintes quiseram enfrentar quando aprovaram a limitaça dos juros reais em 12\%" argumentou ele, tentando convencer os demais Ministros a aderir à tese da auto - aplicabilidade.

Entretanto, até hoje não há lei complementar, apenas o que se observa é a mora legislatoris que já assume foros de contumácia, na certeza de que há mais de nove anos, e já por très legislaturas, o Congresso Nacional persiste em procrastinar a edição da lei complementar, em que pese já haver sido cxortado a tanto por sucessivos oficiamentos do Supremo Tribunal Federal, a partir de mandados de injunção acolhidos para efeito dessa restrita e acanhada finalidade.

E o pior, tem entendido a nossa Magna Corte não ser cabível a determinação de prazo para o suprimento da mora legislativa, tampouco a imposição de preceito cominatório para o caso de persistir a inércia do Congresso Nacional, o que vem, tornando cada vez mais distante tal regulamentaçăo.

Ressalte-se, pois que oportuno, desde a interrupção do ciclo democrático com o golpe militar de 1964, a política econômica dos governos autoritários que se seguiram, associada aos interesses do capitalismo financeiro nacional e internacional, concedeu aos bancos e às instituições linanceiras o monopólio da usura em nosso País, privilegiando indecorosamente o capital especulativo em detrimento do setor industrial e produtivo da economia, tudo com as seqüelas da mais perversa nocividade social.

É o que assevera Carlos Roberto Siqueira"2, "enquanto persistir a orgia dos juros astronômicos e a chamada ciranda financeira, que enriquece poucos, degenera em perniciosa especulaça, penaliza o capital produtivo, amplia os indices de inadimplencia, multiplica os casos de falencia e de concordata de empresas brasileiras, aumenta os niveis de desemprego e, de um modo geral, cmpobrece o conjunto da naçăo e esvaziam-se esses principios constitucionais vetores da democratização da economia nacional."

O próprio Supremo Tribunal Federal, ao julgar a ADIn n. ${ }^{\circ} 4$, decidiu que o limite de $12 \%$ ao ano, previsto, para os juros reais, pelo parágrafo $3^{\circ}$ do artigo 192 da Constituição Federal, depende da aprovação da lei

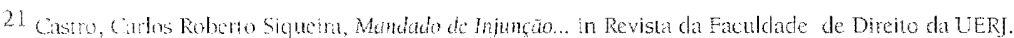


Complementar regulamentadora do Sistema Financeiro Nacional, a que se referem o "caput" e seus incisos do mesmo dispositivo, autorizando, portanto, o monopólio da usura pela classe dos banqueiros em nosso País. E a grande maioria dos juízes, para não verem suas decisões reformadas mantém tal entendimento.

Entretanto, já existe uma consciência social falando mais forte, o que se pode constatar pelas decisōes que vem ocorrendo no Tribunal de Alçada do Rio Grande do Sul, quando se manilesta nos seguintes termos:

"Não é desconhecida a posição do STF, mas esta Câmara, com respeito, vem. divergindo, por entender absolutamente clara a norma contida na Lei Maior, que nenhuma lei complementar poderá melhor explicar, ou contrariar. A EC 3 referida no apelo, näo impede o juiz de decidir contrariamente, o que se tornaria ofensa aos principios de independència de cada julgador. Além do mais, a emenda trata de aços de constitucionalidade de lets, o que muito difere da inconsticionalidade de um ato nomativo de órgão de administraçäo financeira. No julgamento da Adin. N." 4-7, houveram quatro notaveis votos divergentes, o que não torna pacifica a questao, podendo voltar a ser suscitada brevemente, jâ que tarda muito a lei complementar, passados ja 9 anos da entrada em vigência da Carta. A sociedade brasileira premida pela usura, sem exemplos alhures, certamente cobrará posiçăo do Judiciario, ante a flagrante inércia do Legislativo."

É preciso pois, acreditar na Justiça e crer que o Direito caminha de mãos dadas com a sociedade, sempre buscando a pacificação social e tentando encontrar soluçöes para os abusos cometidos!!!

\section{CONCLUSÃO}

A

s obrigacöes foram feitas com o intuito de serem cumpridas, no entanto na maioria das vezes, o inadimplemento ocorre por falha do próprio sistema estrutural, pois admitir que sejam utilizadas as elevadas taxas que as instituicooes linanceiras estão fazendo incidir sobre os contratos de financiamento, além de ilegal e anulável, é servir de conduta geradora de ilícito, perfeitamente reparável e com fundamento no ant. 1531 do Código 
Civil de Delesa do Consumidor (arts. 39 e 51), pois as empresas, tem uma função social a cumprir, aliada à produção e seus consectários de projeção na sociedade.

Näo é demais recordar que os bancos e as instituições financeiras obtiveram o monopólio da usura em nosso País, passando a explorar, com a cumplicidade governamental, a agiotagem consentida e privilegiada. O resultado dessa política perversa e anti - social todos conhecem: o capital especulativo e inflacionário implantou no pais um verdadeiro caos social, prevalecendo cada vez mais a fome e desemprego, causando a quebra da atividade produtiva.

Urge que o Poder Legislativo elabore a Lei Complementar, o mais urgente possivel, para regular definitivamente a aplicação de juros, estabelecido pela nossa Lei Maior, para que verdadeiramente ela se cumpra!

\section{BIBLIOGRAFIA}

NLVM, Agostinho. Da Inexecução das Obrigaçes e suas Conseqüencias. $5^{a}$ ed., São Paulo: Saraiva, 1980

ANTUNES VARUIA. Direito das Obrigaçoes. V4., $9^{\mathrm{a}}$ ed., Rio de janeiro: Forense, 1977. BRVI AQUTA, Clovis. Direito das Obrigaçöes. V.4, $9^{\mathrm{a}}$ ed., Rio de Janeiro: Francisco Alves, 1955.

CARVAIIIO DE MENDONCA Doutrina e Prática das Obrigações. V. I., $4^{a}$ ed., Rio de Janeiro: Freitas Bastos, 1956

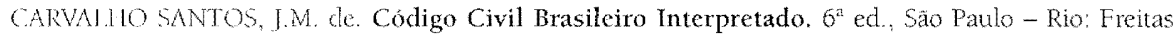
Dastos, 1955 .

COSTA, Mario de Almeida. Direito das Obrigaçoes. $6^{a}$ ed., Coimbra: Almedina, 1994.

DINIZ, Maria Helena. Teoria Geral das Obrigaçóes. VII, $9^{a}$ ed. São Paulo: Saraiva, 1995

DOWTR, Nelson G. Bassil. Curso Moderno de Direito Civil. V.II., Săo Paulo; Nelpa, 1996.

GOMls, Orlamilo. Obrigaçoes. $1^{\mathrm{a}} \mathrm{ed}, \mathrm{ed}$, Rio de janeiro: Forense, 1996.

LIMONGI TRANCA. Manual de Direito Civil. V III, Säo Paulo: Revistas dos tribunais, 1995)

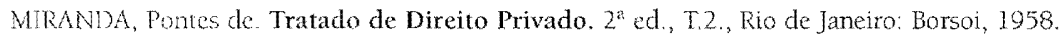

MONTURO, Washington de Baros. Direito das Obrigaçoes. $5^{a}$ ed, São Paulo: Sarava, 1968.

RODRIGUTS, Silvio, Direito Civil. VII, $3^{\text {ed }}$, Săo apulo: Max Limonad, 1968.

ROTOND], Mário. Instituzioni di ditto privato. $5^{\text {a }} \mathrm{ed.}$. Milão: Ambrosiana, 1945.

SIRPA IOPES Curso de Direito Civil, V. 11., $4^{\mathrm{a}}$ ed., Rio de Janeiro: Freitas Barros, 1966. 